\title{
Lessons from the Roswell Park Bone Marrow Transplant Aspergillosis Outbreak
}

Between April 1982 and March 1983 an outbreak of aspergillosis occurred among bone marrow transplant patients in a newly opened bone marrow transplant unit (BMTU) at the Roswell Park Memorial Institute. Rotstein and his colleagues, in an article in this issue, present the first scientific data about this important event. ${ }^{1}$ Their primary contribution is a case-control analysis of risk factors predisposing to aspergillosis comparing the 10 BMTU patients who developed aspergillosis with the 16 who did not. Since the number of analyzed variables surpasses the number of patients involved, these authors can be said to have mined the material close to its limits. Their meticulous and complex multivariate analysis found the most significant association with aspergillosis to having, as the underlying disease, chronic myelogenous leukemia (CML) or aplastic anemia. Bone marrow transplant recipients with CML tend to be older than those with acute leukemia increasing the incidence of graft vs. host disease and cytomegalovirus infection, both of which predispose to infection. The duration of granulocytopenia was the next most important predictor (although 4.7 days for patients transplanted in 1977 to 1980 is unusually short). Also significant was duration of antimicrobial therapy. Antibacterial therapy reduces nasal bacterial flora which may increase nasopharyngeal Aspergillus colonization making aspiration hazardous. The Roswell Park data are consistent with the view that aspergillosis is a function of severity and duration of immunosuppression with antibacterial therapy possibly playing an independent aggravating factor. A further independent predisposing factor, exposure to airborne Aspergillus spores, was not directly assessed.

Most readers of this article will be more interested in

From the Infection Control Program, University of Minnesota Hospitals and Clinics, Infectious Diseases Section, Department of Medicine, Department of Laboratory Medicine and Pathology and the Division of Epidemiology, School of Public Health, University of Minnesola, Minneapolis, Minnesota.

The author acknowledges Leesa Schofield for word processing assistance.

Address reprint requests to Frank S. Rhame, MD, Box 421, Mayo Memorial Building, University of Minnesóta Hospitals, Minneapolis, MN 55455. why the aspergillosis outbreak occurred. Rotstein and colleagues conclude that the main cause was an overrepresentation of CML patients among their patients transplanted in the BMTU. The authors indicate that no environmental source was found and do not directly address the potential impact of the BMTU air filtration system. Some relevant information was presented. The BMTU and the satellite air filtration systems had $10 \%$ efficiency, roll-type filters. An undescribed number of $.4 \mathrm{~m}^{3}$ environmental air samples showed 0 to 5 nonspeciated Aspergillus colonies with similar levels in the BMTU, satellite building and outside air. But no multivariate analysis of risk factors, considering BMTU location as an independent variable, was presented and the air filtration system in use for the remaining 21 patients was not described.

Readers acquainted with the adverse publicity suffered by Roswell Park and the pending litigation may be disappointed by the brevity of this analysis. Since the Roswell Park episode has had a substantial impact on the design of bone marrow transplant centers in the United States, it is desirable to have more complete information about these events. I will attempt an account herein based on the modest public record available to me: two articles in the New York Times (November 3, 1983) (June 5, 1979), an AP wire story (Minneapolis Star and Tribune, June 6, 1984), the report of the New York State Department of Health², and filed information from lawsuits. ${ }^{3.4}$ Unfortunately, with litigation underway, it will probably be many years before a complete assessment can be made. It is quite possible, particularly if the lawsuits are settled out of court, that the participants will never present a detailed account in the scientific literature.

The Roswell Park Memorial Institute is a 277-bed cancer center operated by the New York State Department of Health (NYSDH). The Institute began bone marrow transplantation in September 1977. In mid-1981 the hospital asked that the air ventilation system be upgraded although I am unaware of specifically what was requested. The New York State Office of General Services indicated that the money was allocated and the State was ready to proceed with construction, but there was, at the time, 
competition for funding to ease overcrowding in prisons. The unit opened in April 1982 with $10 \%$ efficiency filters. By June 31, 1982, when 10 patients had been transplanted in the BMTU, three deaths in patients with aspergillosis were recognized. The first air samples were obtained in August 1982. By November, 5 aspergillosis cases out of 17 transplanted patients were recognized. No more cases were diagnosed during the ensuing 3 months. In March and April of 1983, 5 aspergillosis cases were recognized and the entire unit was shut down. In October 1983, the NYSDH began its investigation. This investigation began, at least in part, because of critical reports broadcast by radio station WBEN in Buffalo. In June 1984, the NYSDH report was made public. ${ }^{2}$ Lawsuits have been filed against the State of New York on behalf of 2 patients seeking aggregate damages in excess of $\$ 2,500,000 .^{3,4} \mathrm{At}$ least 2 additional suits have been filed (Sullivan RT, personal communication, August 7, 1985).

Ultimately, these lawsuits should turn on the following questions. Was the low efficiency of the filtration system responsible for the BMTU cases? Should it have been known in July 1982 that it is inappropriate to perform bone marrow transplantation in units without at least moderate efforts to provide spore-free air? Should the unit have been shut down earlier in the course of the outbreak? In my opinion, the plaintiffs should have to prove all three points in order to prevail.

With respect to the role of the ventilation system, the NYSDH report suggests a different conclusion from Rotstein et al. ${ }^{2}$ The report agreed that underlying diagnosis of CML or aplastic anemia and duration of leukopenia constituted the best set of predictive variables. However, the report also concluded that "after controlling for these characteristics, transplantation in the BMTU was still significantly associated with developing aspergillosis. When location at the time of transplant was considered in the model, the predictive ability of the model was significantly improved" $(p<0.02)$. The NYSDH report also described an assessment of ventilation rates in the BMTU rooms by George Mallison. One of the rooms had an air change rate of $7.6 / \mathrm{hr}$ and the remaining rooms ranged between 1.0 and 2.5/hr. Room-specific aspergillosis attack rates and air change rates, considered in a weighted linear regression analysis, demonstrated a significant association $(p<0.02)$ which held up even if the room with the highest air change rate was excluded $(\mathrm{p}<0.03)$. The report finally describes substantial adjacent off-campus construction during the BMTU outbreak. In the first half of 1982 , excavation at the hospital station of the Buffalo rapid transit system involved movement of $22,000 \mathrm{~m}^{3}$ of dirt. Between October 15, 1982 and September 1, 1983, the new Buffalo General Hospital construction involved excavation of $23,000 \mathrm{~m}^{3}$ of dirt. Between November 1982 and May 1983 an apartment building adjacent to the hospital was demolished. These construction sites were west of the hospital and the prevailing winds were from the southwest. The NYSDH report explicitly acknowledged that the etiology of the outbreak could not be determined but also clearly suggested that the low efficiency of the BMTU filters and simultaneous external construction are likely to have been responsible.
The NYSDH report also criticized many features of Roswell Park's Infection Control Program. Unspecified protocols were described as being out of date. Several omissions were specifically cited: not providing final autopsy reports to infection control staff, not compiling organism-specific incidence rates of nosocomial infection, performing analyses surveillance data by hand, not computer, and the failure to report the aspergillosis outbreak directly to the NYSDH.

Ultimately, conclusions about the cause of the BMTU outbreak rest on the following jucigments. Is CML really such a potent predisposing factor for aspergillosis? Or did CML emerge as significant because occasional unrelated factors are expected to appear statistically significant when a large number of variables are analyzed? On the other hand, how could the combination of low efficiency filtration and adjacent construction cause the BMTU outbreak when the satellite building had a similar filtration system and there was also substantial adjacent construction during 1981?

Whatever is the true cause of the BMTU outbreak, the differences between the reports of Rotstein et al and NYSDH force painful questions on this editorial writer. It is hard to escape concern that a scientific submission was modified to reduce the impact of pending litigation. Is there any reason to suspect the NYSDH of bias? It is, in fact, very hard to find anyone free of conflict of interest: there has been enough aspergillosis at the University of Minnesota Hospital to cast doubts on my willingness to critcize a sister institution. ${ }^{3}$ Recognizing that conflicts of interest are inevitable, we seek to mitigate their impact by requiring their disclosure. It has become accepted practice that scientific submissions concerning medications or devices in which an author has a financial interest should include an explicit description of that interest. ${ }^{4}$ I submit that this disclosure process should be extended to the presentation of scientific information by participants in related litigation.

The most important lesson of the Roswell Park outbreak is that bone marrow transplantation in units supplied by crudely filtered air is unacceptable. More than a few bone marrow transplant centers in the United States, reacting to the adverse publicity and litigation arising from the Roswell Park outbreak, have elected to provide HEPA laminar airflow rooms for bone marrow transplantation. However, top-of-the-line bag filters remove more than $99 \%$ of fungal spores. The use of an increased air change rate may accomplish most or all of the antifungal benefits of laminar airflow. These issues and the need for additional measures remain important research topics.

\section{REFERENCES}

1. Rotstein C, Cummings KM, Tidings J, et al: An outbreak of invasive aspergillosis among allogeneic bone marrow transplants: A case-control study. Infect Control 1985; 6:347-355.

2. Bureau of Communicable Disease Control, Division of Community Health and Epidemiology, New York State Department of Health. Epidemiologic Investigation of Aspergillosis Roswell Park Memorial Institute. June 1984.

3. Cristoff $v$. State of New York. New York State Court of Claims $\$ 68831$.

4. Watrous v. State of New York. New York State Court of Claims *69422.

5. Peterson PK, McGlave P, Ramsay NKC, et al: A prospective study of infectious diseases following bone marrow transplantation: Emergence of Aspergillus and cytomegalovirus as the major causes of mortality. Infect Control 1983; 4:81-89.

6. Relman AS: Dealing with conflicts of interest. $N$ Engl J Med 1984; 310:1182-1183. 